\title{
Adenoviral-Mediated Gene Transfer into Bone Marrow: An Effective Surgical Technique in Rat
}

\author{
J.C. Rodriguez-Lecompte ${ }^{a} \quad$ G.A. Romero-Perez ${ }^{d} \quad$ G. Ramirez-Yañez ${ }^{b}$ \\ K. Ask ${ }^{c}$ J. Gauldie \\ aDepartment of Pathology and Microbiology, Atlantic Veterinary College, University of \\ Prince Edward Island, Charlottetown, P.E.I., ${ }^{\text {b }}$ Department of Oral Biology, Faculty of \\ Dentistry, University of Manitoba, Winnipeg, Man., and 'Pathology and Molecular Medicine, \\ Nuclear Medicine and Medicine, Center for Gene Therapeutics, McMaster University, \\ Hamilton, Ont., Canada; ${ }^{d}$ Department of Physiology I, Kansai Medical University, \\ Moriguchi, Japan
}

\section{Key Words}

Adenoviral vectors - Bone marrow · Gene transfer - Marrow fibrosis - Transforming growth factor-beta 1

\begin{abstract}
Background: The role of transforming growth factor-beta 1 (TGF- $\beta_{1}$ ) in the onset of bone marrow fibrosis has been confirmed in some animal models. To further understand the genetic expression of some myeloproliferative disorders affecting marrow stem cells, however, it is necessary to develop a specific and reliable procedure to deliver modified adenoviral vectors into the bone marrow cavity. The aim of this paper is to report a surgical technique designed to deliver an adenoviral vector-mediated gene expressing TGF- $\beta_{1}$ into the bone marrow of rat femurs. Methods: Forty-two Sprague-Dawley rats were used in the study. Rat femurs were exposed and the compact and trabecular bones at the proximal head removed. An intrabone marrow injection of a mutated TGF- $\beta_{1}$ adenoviral vector, a null adenoviral vector, or PBS was delivered into the bone. Three groups were accounted ( $n=14$ per group): fibrogenic and positive and negative controls. The quality of the surgical entrance was assessed by means of computerized tomography and histological changes were assessed by histochemistry. The concentration of TGF- $\beta_{1}$ in the bone marrow was determined by ELISA. Results: The surgical technique was conducted under ideal timing (approx. $10 \mathrm{~min}$ ) and no surgical or postsurgical complications were observed. Computerized tomography revealed no changes in the bone tissue and a clean entrance was delimited through the bone to the bone marrow.
\end{abstract}


$\mathrm{HE}$ and Masson's trichrome staining indicated highly fibrotic areas in the profibrotic group and bone marrow lavage reported a significantly higher concentration of TGF- $\beta_{1}(p<0.05)$ in that same group. Conclusions: The present study confirmed that the proposed surgical technique is an effective method to deliver adenoviral vectors into the femoral bone marrow to investigate the physiopathology of bone marrow fibrosis in rats.

Copyright (C) 2013 S. Karger AG, Basel

\section{Introduction}

Myeloproliferative disorders include diseases such as chronic myelogenous leukemia, polycythemia vera, essential thrombocythemia, idiopathic myelofibrosis or myelofibrosis with myeloid metaplasia (which has been recently renamed as primary myelofibrosis), that are due to abnormal growth of stem cells in the marrow [1]. The bone marrow reaction is thought to be reactive and cytokine mediated. It has been hypothesized that long-term presence of profibrotic cytokines released from these abnormal cells are capable of inducing irreversible changes in bone marrow stromal cells and the extracellular matrix, leading to bone marrow fibrosis and consequently hematological failure [2, 3]. Although the etiopathogenesis of this profound stromal reaction remains equivocal, mediating cytokines such as transforming growth factor-beta 1 (TGF- $\beta_{1}$ ) are believed to be produced by clonal megakaryocytes, monocyte-macrophage cell lineage, or both [4]. However, to date the cause of the excessive fibrosis that is observed in these disorders remains unclear.

Bone marrow gene therapies require targeted transfer of the therapeutic genes into stromal area cells that proliferate and express these genes either in a tissue-restricted or tissue-transient manner [5]. It has been demonstrated that adenoviral vectors have some advantages over other virus systems, which potentially make them ideal candidates for gene therapy. A number of clinical experiments have reported the use of adenoviral vectors in gene therapy with high efficiency of gene transduction [6, 7]. Cells can be infected by the adenovirus at any stage of the cell cycle allowing a transient expression of genes, as the viral genome does not integrate into host chromosomes [7]. Members of our group previously reported a method of marrow stromal cytokine gene transfer to the bone marrow of dogs by direct intramarrow injection of adenoviral vectors, based on the needle aspiration technique used in humans [8]. Although in that experiment the adenoviral cytokine expression at the bone marrow led to compartmentalized expression of growth factors, the animal model presented various technical difficulties [8]. Indeed, one of the difficulties was to justify a large number of dogs to fit the statistical model. Alternatively, our team tried to use mice as the animal model; this approach was based on previous work that injected directly gene-delivering viral vectors into the bone marrow of mice to study hematopoietic cell gene transfer in their native environment [9-11] . However, we found that during the delivery of the gene, our needle was breaking the bone and consequently there was a leakage of the adenoviral vector, which posed a biological risk. In addition, when the number of experimental animals was large, the use of mice as models in experimental bone marrow surgery became less safe to inject a volume of the vector directly into the bone marrow, due to their small size. In contrast, rats seem to be better alternative models as their bodies are large enough to hold more securely during surgery and their bones bigger, which allow a safer delivery of the gene into the bone by injection without the risk of leakage. Furthermore, rats have been previously used as animal models to transfer genes via the portal vein using adenoviral vectors, with no apparent difficulties [12].

TGF- $\beta_{1}$ plays an important role in the development of bone marrow fibrosis $[13,14]$. In this context, TGF- $\beta_{1}$ overexpression and TGF- $\beta_{1}$-induced bone marrow fibrosis can be used 
as validation of the efficacy of any surgical method aiming to deliver a mutated adenoviral vector into that tissue.

The aim of this study is to present an efficient and easier surgical technique to inject an adenovirus-encoded cytokine, TGF- $\beta_{1}$, into the bone marrow of rats that will allow us to express this gene in order to study and characterize its role in bone marrow fibrosis.

\section{Materials and Methods}

Animals

Forty-two Sprague-Dawley rats (average body weight 250 g; Harlan, Indianapolis, Ind., USA) were used in the present work. The animals were randomly allocated to the treatment groups described below. They were maintained under a 12-hour light cycle and provided with food and water ad libitum. All animal care protocols used during the experiment were conducted according to the Canadian Council on Animal Care Guidelines [15].

\section{Recombinant Adenoviral Vectors}

Two adenoviral vectors were used: an encoding TGF- $\beta_{1}$ (AdTGF- $\beta_{1}$ ) and a null adenovirus (AdDL70), which was used as positive control. Adenovirus was constructed following the methodology described by Sime et al. [16] and Bett et al. [17]. Briefly, AdTGF- $\beta_{1}$ sequence was isolated by PCR from mRNA extracted from rat lung tissue, cloned into a shuttle plasmid and cotransfected in human embryonic kidney 293 cells (The American Type Culture Collection; Rockville, Md., USA) to generate the adenoviral vector. Adenoviral preparations were purified by $\mathrm{CsCl}$ gradient centrifugation and PD-10 Sephadex chromatography (Amersham Pharmacia, Baie d'Urfé, Qué., Canada) and plaque tittered on the same 293 cells as recommended by Xing et al. [18]. To confirm the transgene expression, human A549 alveolar epithelial cells (type II alveolar cell carcinoma; ATCC) were infected with either purified AdTGF- $\beta_{1}$ or AdDL70 adenoviruses; 3 days later, supernatants were taken and analyzed by enzyme-linked immunosorbent assays (ELISA; R\&D Systems, Minneapolis, Min., USA) confirming TGF- $\beta_{1}$ overexpression. Experimental protocols carried out for the use of recombinant DNA or biohazardous materials were reviewed and approved by the Biosafety Committee of McMaster University (AUP-060313).

\section{Anesthesia and Surgical Technique}

Animals were anesthetized with isoflurane delivered by an anesthetic machine (V3000PK; Parkland Scientific, Coral Springs, Fla., USA). During the surgical and recovering time, the animals were positioned on a warm pad stabilized at $37^{\circ} \mathrm{C}$. The proximal areas on both thighs were shaved, washed and disinfected with a povidone-iodine cleansing solution (Proviodine Solution ${ }^{\circledR}$; Alcon Laboratories Inc., Fort Worth, Tex., USA) (fig. 1a). After assessing the depth of anesthesia - by checking the animal's toe pinch and corneal reflex, as well as rate and pattern of respiration - a small incision (approx. $1.5 \mathrm{~cm} \mathrm{long)} \mathrm{was} \mathrm{made} \mathrm{on} \mathrm{the} \mathrm{surgical} \mathrm{area}$ to expose the femur (fig. 1b). Briefly, the skin was cleared from tissue underneath using Metzenbaum scissors and the linea alba identified, which corresponds to the intermuscular septus and separates anatomically the biceps femoral muscle from the superficial gluteal muscle (fig. 1c). These muscles were separated from the intermuscular septus with Metzenbaum scissors, keeping the integrity of the muscles. Access to the anterior face of the femur throughout its length was created, and the major trochanter to the femoral distal metaphysis identified. A small hole was opened at the proximal portion of the femur using a medium-sized round bur, perforating the bone until a decrease in resistance indicated the bone marrow area was reached (fig. 1d). Then, a dental endodontic file size 30 (FC Medical Device, St-Laurent, Que., Canada) was used to further delimit the surgical entry (fig. 1e). Finally, the opened area was cleared by blowing $500 \mu$ l of air into the canal with a 1-ml syringe with a sterile 25-gauge needle (BD, Mississauga, Ont., Canada) (fig. 1f). Through the canal entry, an adenovirus vector was delivered into the bone marrow using a syringe similar to that described above (fig. 1 g). Fourteen animals received $1 \times 10^{8} \mathrm{PFU} / 5 \mu \mathrm{l}$ of AdTGF- $\beta_{1}$ (profibrotic group) and 14 animals received $1 \times 10^{8} \mathrm{PFU} / 5 \mu \mathrm{l}$ of AdDL70 (positive control group). In addition, 14 animals received an injection of PBS (negative control group). Immediately after delivering either the adenoviruses or PBS (fig. 1h), the surgical entrance was sealed with a biocompatible cyanoacrylate (Vetbond ${ }^{\circledR}, 3 \mathrm{M}$ ) (fig. 1i) and the incision sutured with 4-0 coated VICRYL ${ }^{\circledR}$ (Johnson \& Johnson International ELC, Madison, Wisc., USA) (fig. 1j) or Reflex wound clips 9 (Fine Science Tools, Vancouver, B.C., Canada) (fig. 1k). At the end of the surgery (fig. 1l) 


\section{European \\ Surgical \\ Research}

\begin{tabular}{l|l}
\hline Eur Surg Res 2013;50:282-291 \\
\hline DOI: $10.1159 / 000351336$ & $\begin{array}{l}\text { ( 2)13 S. Karger AG, Basel } \\
\text { www.karger.com/esr }\end{array}$ \\
\hline
\end{tabular}

Rodriguez-Lecompte et al.: Adenoviral-Mediated Gene Transfer into Bone Marrow: An Effective Surgical Technique in Rat
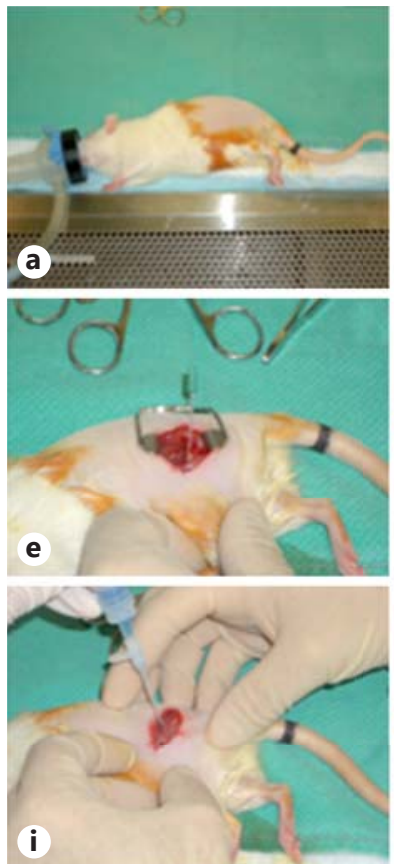
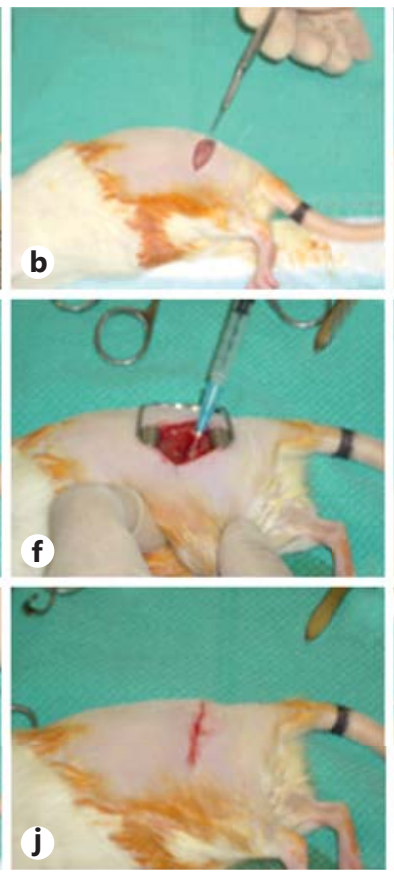
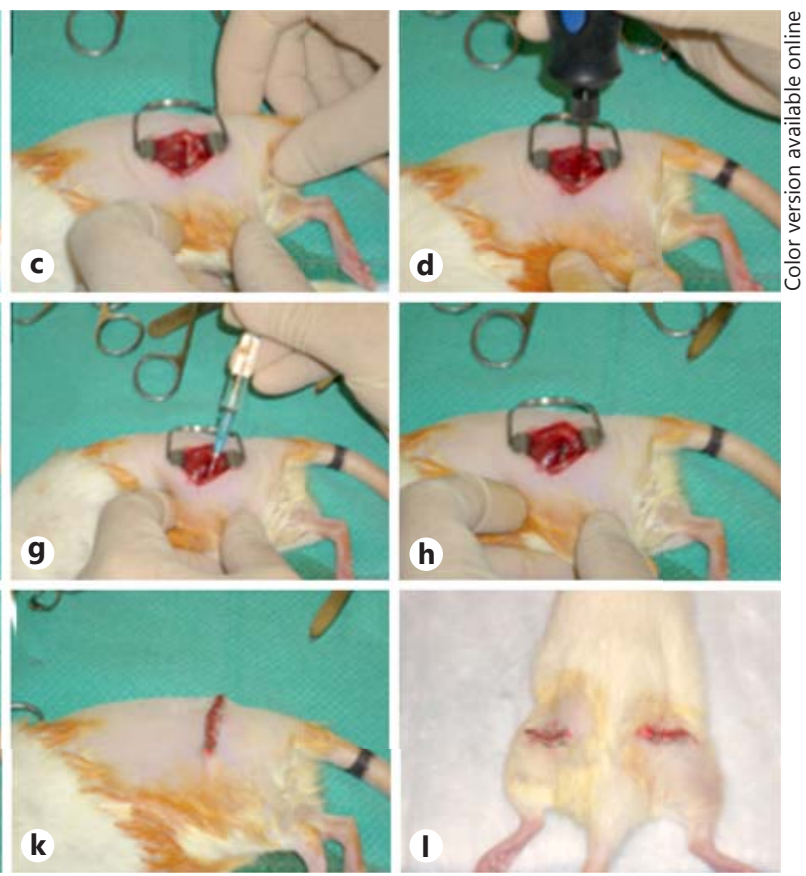

Fig. 1. Photographs of the surgical technique portraying the procedure and steps for intrabone marrow gene delivery. a Rat on the anesthetic machine with isoflurane. b Incision $1.5 \mathrm{~cm}$ long. c Muscle separation and exposition of the femur. d A small hole made in the proximal femur. e A dental endodontic file size 30 was inserted through the hole into the marrow cavity to make a canal. $\mathbf{f}$ The canal is cleared by injecting $500 \mu \mathrm{l}$ of air into the canal. $\mathbf{g}$ The adenoviral vector delivery by injection into the bone marrow cavity. $\mathbf{h}$ Bone cavity after inoculation. $\mathbf{i}$ The hole was sealed with sterile histocompatible cyanoacrylate glue. The incision was closed with either one or two 4-0 coated VICRYL sutures (j) or wound clips Reflex 9 (k). I Recovery of the animal after surgery.

all animals received $90 \mu \mathrm{g}$ of Temgesic ${ }^{\circledR}$ subcutaneously (buprenorphine hydrochloride), followed by 300 $\mathrm{mg} / \mathrm{kg}$ of Tylenol ${ }^{\circledR}$ orally (acetaminophen) every $12 \mathrm{~h}$ for the first $48 \mathrm{~h}$. Sulfamethoxazole (30 mg/kg/day) plus trimethoprim ( $6 \mathrm{mg} / \mathrm{kg} /$ day) was also provided for 7 days to control the infection risk. The animals were monitored twice daily during the 2 weeks following surgery.

Fourteen days after surgery all animals were euthanized by exsanguination under general anesthesia as described above, and their femurs harvested for analysis. Briefly, the abdomen of rats was shaven and cleaned from the xiphoid to the pubic area with a surgical clipper blade No. 40. With even pressure a clean skin incision was made, the abdominal muscle layer picked up, and another tiny incision made with the scalpel blade on the linea alba to perforate the peritoneal cavity. With scissors an incision was cut upwards and downwards along the linea alba through the peritoneum to expose the abdominal contents. Then, the portal vein close to the liver was localized and cut with a small pair of scissors. After no vital signs were detected, the femurs were removed, manually defleshed and used for computerized tomography (CT) scanning and tissue sections.

\section{CT Scanning}

Femurs from all rat groups were analyzed by CT scanning. High-resolution volumetric X-ray CT imaging was conducted using 80-kVp X-rays at $0.24 \mathrm{~mA}$, on a Gamma Medica X-SPECT machine (Gamma Medica, Northridge, Calif., USA). Raw projection data were acquired over $360^{\circ}$ into 512 angles using a 2,048 $\times 2,048$ detector matrix ( $48 \times 48 \mu \mathrm{m}$ pixel size). Then, volumetric images were reconstructed using Exxim COBRA software (Exxim Computing Corporation, Pleasanton, Calif., USA) into $256 \times 256 \times 768$ pixel volumes $(55 \times$ $55 \times 55 \mu \mathrm{m}$ ) and scaled to Hounsfield units for subsequent analysis. The CT scanning time was approximately $1 \mathrm{~min}$ per sample. Scanned images were visualized on the computer screen by means of computerized 
software (Amira Visage Imaging, San Diego, Calif., USA). CT-scanned images were subjectively analyzed by three of the authors in a blinded fashion. For this, all the images were saved in a separate file with no treatment labels and a code was maintained under lock by the radiology technician.

Histology

Seven femurs from each group were processed and histology sections were obtained. For that, tissues were fixed in $10 \%$ formalin for $48 \mathrm{~h}$, decalcified in citric acid, embedded in paraffin and sectioned $(5 \mu \mathrm{m}$ thick). Histology sections were stained for HE and Masson's trichrome. Digital photographs were obtained and visualized on the computer screen using Photoshop computer software (Adobe Systems Inc., San Jose, Calif., USA). Bone marrow histology was subjectively evaluated for the presence of fibrotic areas.

Enzyme-Linked Immunosorbent Assays (ELISA)

The other seven femurs from each group were processed for ELISA. To that end, the proximal and distal portions of the femurs were cut off and $100 \mu \mathrm{l}$ of $1 \times$ PBS flushed through the bone marrow area using a 1-ml syringe in order to detach the tissue. The lavage obtained from each sample was centrifuged at 2,500 rpm for $5 \mathrm{~min}$ and the obtained supernatant was stored at $20^{\circ} \mathrm{C}$ until use. The concentration of TGF- $\beta_{1}$ was individually assessed by ELISA.

Statistical Analysis

TGF- $\beta_{1}$ concentration for the three groups, profibrotic (AdTGF- $\beta_{1}$ ), positive (AdDL70) and negative (PBS), were contrasted by one-way analysis of variance using SPSS statistical package (version 11.0; SPSS Inc., Chicago, Ill., USA). A 95\% level of confidence was used to determine statistical significance $(p<0.05)$.

\section{Results}

\section{Efficiency of the Surgical Technique}

The surgical time was approximately 10 min per animal and no complications were recorded at any time. Average blood loss was estimated approximately at $0.5 \mathrm{ml}$, which is considered neither significant nor a factor affecting the red cell values of rats. The instruments adapted and used for surgery were effective and allowed an easy and clean procedure. The surgical area and prepared entrance were found to be appropriate and allowed a safe procedure. The muscles attached to the femur, the biceps femoris and the gluteus maximus, were moved apart and easy access to the proximal-lateral area of the femur was attained. The entrance prepared to access the bone marrow area was big enough to introduce a needle and inoculate the adenoviral vector.

Monitoring of the healing process of the rats was similar to that for common complications in human patients undergoing orthopedic surgeries. After suturing the surgical area, all animals resumed physical activity within 15 min. Observation of postsurgery recovery showed that mobility was normal, weight was maintained and no signs of infection or inflammation were observed. Moreover, daily assessment of body temperature (hyperthermia or hypothermia), social behavior (alertness), appetite (feed intake), and agility (absence of pain and lethargy), showed that the animals achieved full recovery during the period between surgery and euthanasia.

\section{CT Scanning}

The morphological characteristics on the anteroposterior CT were considered in the study. To compare the anatomical geometry, the area analyzed for evaluation was focused on the medullary cavity between the canal width below the lesser trochanter and the endosteal width at the isthmus. It was arbitrarily defined as the difference between the canal diameter sections. CT scanning confirmed the trajectory of the surgical entrance below the lesser trochanter (fig. 2a). Although no bone density analysis was performed at this point, a larger 
Rodriguez-Lecompte et al.: Adenoviral-Mediated Gene Transfer into Bone Marrow: An Effective Surgical Technique in Rat

Fig. 2. CT scans depicting the surgical entrance into the bone marrow area of the femur (a) and a wider bone marrow area (b) in a femur inoculated with the TGF- $\beta_{1}$ adenoviral vector (arrow) compared with a sample (c) inoculated with PBS.
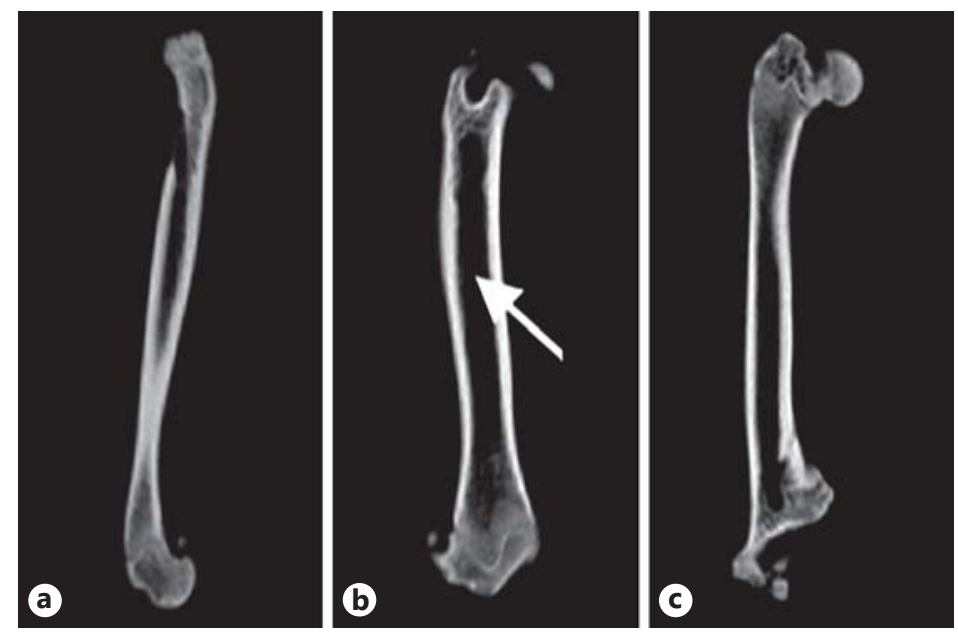

marrow cavity in the endosteal width at the isthmus was observed in the profibrotic group after 14 days of the adenoviral inoculation (fig. 2b), compared with the other two groups (fig. 2c).

\section{Histological Observations}

At day 14 after the intrabone marrow of animals was transfected with AdTGF- $\beta_{1}$, normal and pathologically altered tissue specimens from the diaphysis femoral periosteum, the compact bone, the trabecular bone and the medullar cavity of the rats were examined. The biological changes of the specimens were assessed by structural changes involving collagen deposition and presence or absence of fibrotic areas obliterating the marrow cavity. To define the biological process of fibrosis, the structural properties of bone marrow tissue specimens were categorized as unchanged (nondestructive), moderately changed (mildly destructive) and severely changed (destructive) by light microscopy combined with biochemical and immunological techniques.

The trajectory of the surgical drill entrance and relevant changes in the marrow cavity are displayed in figure 3 . A cross-section of the bone showed the hole drilled throughout the periosteum, compact bone and medullary cavity (fig. 3a), and the semiempty medullar cavity, indicating a delimited surgical entry further created with a dental endodontic file. More extensive fibrotic (destructive) areas in the bone marrow were visible in most animals infected with AdTGF- $\beta_{1}$ (fig. 3d) compared with those stimulated with either AdDL70 (mildly destructive) (fig. 3b) or PBS (nondestructive) (fig. 3c). Light microscopy analysis showed changes in the bone marrow cavity such as a decreased amount of hematopoietic cords, sinusoids, endothelial cells, adipocyte and megakaryocytes, all of which were associated with structural changes (fig. 3e). Also, throughout the marrow trabeculas, large fibrotic areas showing strong inflammatory responses - presence of neutrophils, recent osteosynthesis and osteosclerosis, and new collagen deposition - were observed (fig. 3f).

\section{TGF- $\beta_{1}$ Concentration in Supernatants}

The ELISA of the supernatants obtained from the bone marrow showed that at day 7 there were no statistical differences between groups ( $p>0.05)$. However, at day 14 TGF- $\beta_{1}$ concentrations were significantly higher $(\mathrm{p}<0.05)$ in the profibrotic group compared with those in the positive (AdDL70) and negative control (PBS) groups (fig. 4). 

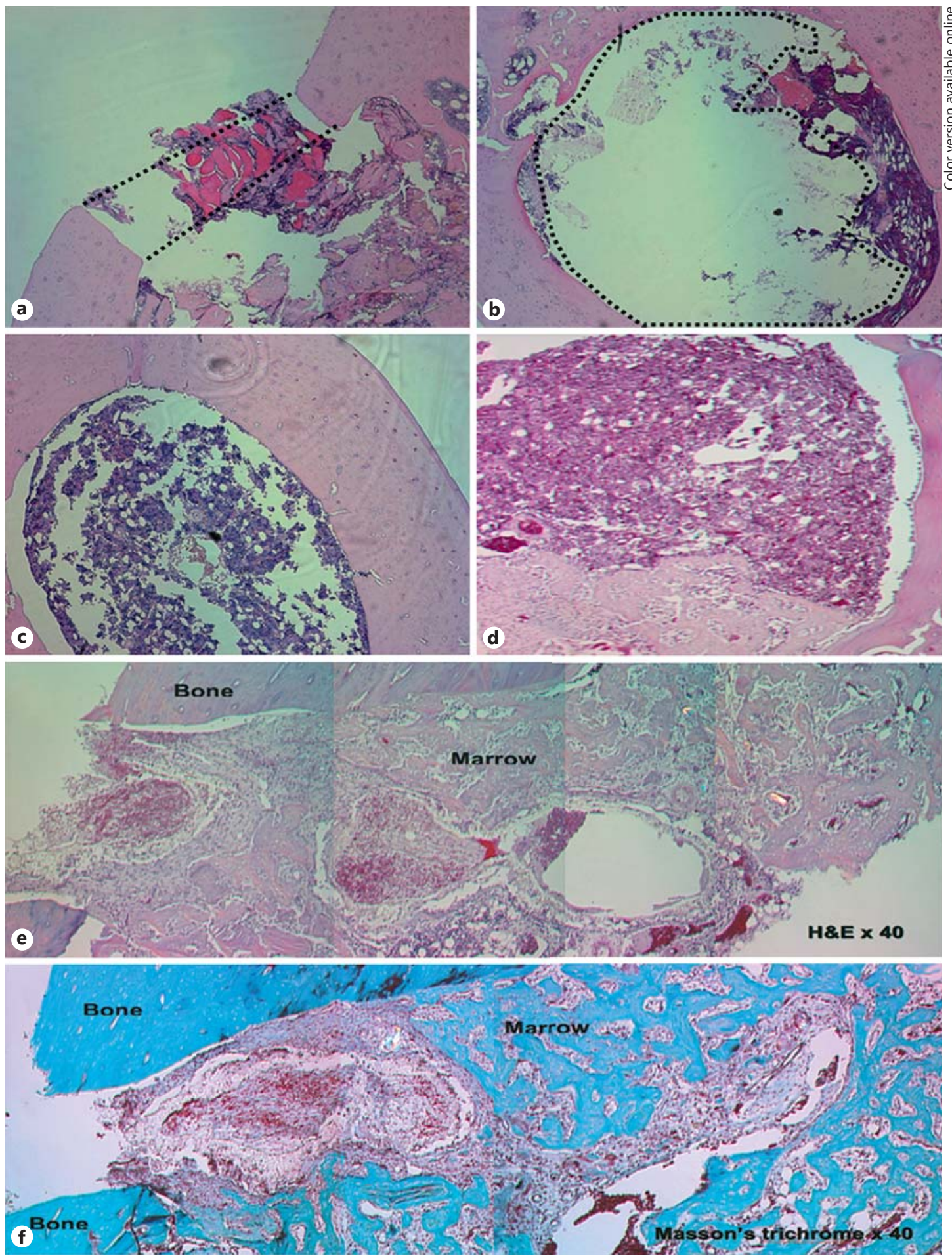

Fig. 3. Photographs of histology sections stained with HE. a The trajectory of the surgical entrance into the bone marrow. b Bone marrow area of a sample inoculated with a null adenoviral vector (AdDL70; positive control). c Bone marrow area of an animal from the sham-operated group. $\mathbf{d}$ Bone marrow area of a sample inoculated with the adenoviral vector encoding fibrogenic cytokine TGF- $\beta_{1}$. e Light microscopy analysis after the intrabone marrow of animals was transfected with AdTGF- $\beta_{1}$ showed changes in bone marrow cavity associated with structural changes. $\mathbf{f}$ Large fibrotic areas throughout the marrow trabeculas with new osteosynthesis and osteosclerosis and new collagen deposition were observed (section stained with Masson's trichrome). All 4 photographs are tissues 14 days after surgery. 
Rodriguez-Lecompte et al.: Adenoviral-Mediated Gene Transfer into Bone Marrow: An Effective Surgical Technique in Rat

Fig. 4. Graphic illustration of TGF- $\beta_{1}$ concentration in bone marrow lavage of those animals inoculated with PBS (negative control), the null adenoviral vector AdDL70 (positive control) and TGF- $\beta_{1}$ adenoviral vector. A statistically significant increase in the concentration of TGF- $\beta_{1}$ was computed 14 days after surgery in the animals inoculated with the TGF- $\beta_{1}$ adenoviral vector. Results are presented with mean values and standard errors calculated from experiments with 4 rats from each group in triplicate (* $\mathrm{p}<0.05)$.

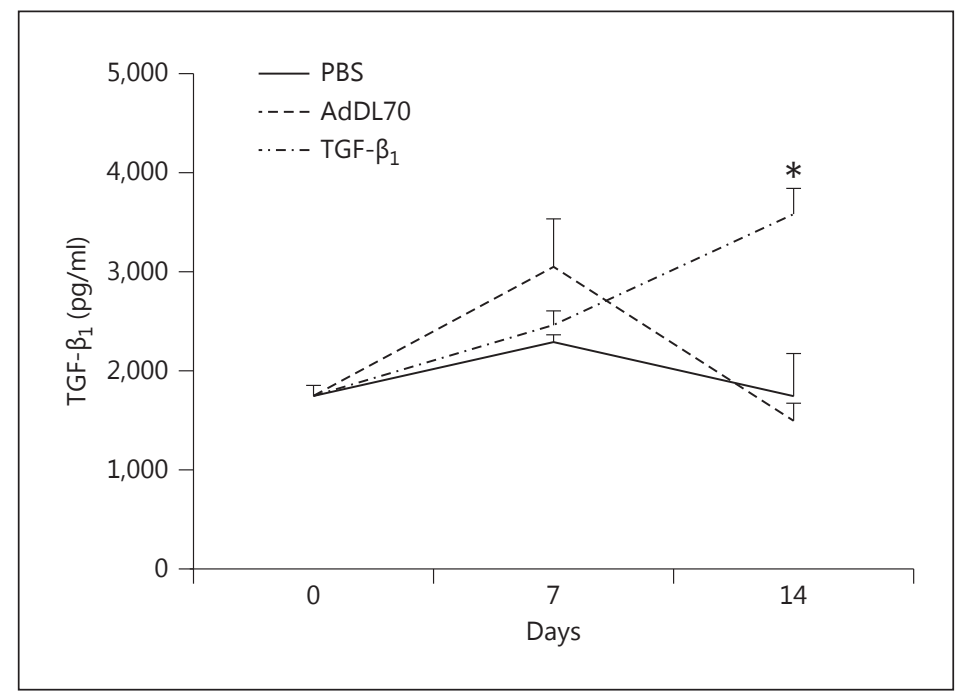

\section{Discussion}

Currently, there is an increasing interest in using gene therapy to treat various myeloproliferative diseases [for review, see 19]. The present study demonstrated that the delivery of the TGF- $\beta_{1}$ gene into the bone marrow of rats resulted in fibrosis. Previously, TGF- $\beta_{1}$ has been shown to play a prominent role in the induction of fibrosis [20]. TGF- $\beta_{1}$ is secreted as latent protein that requires activation to become biologically active, negatively regulates the progenitor cell growth and favors the deposition of extracellular matrix in different tissues [21]. It has been assumed that long-term presence of TGF- $\beta_{1}$ putatively induces irreversible changes in bone marrow stromal cells and the extracellular matrix, leading to bone marrow fibrosis and consequently hematological failure in bone marrow [22]. Furthermore, bone marrow fibrosis is believed to be a significant marker of progression of myelofibrosis [23]. Although Kaviratne et al. [24] demonstrated that fibrosis activation mechanism is independent of TGF- $\beta_{1}$, more recently Kreipe et al. [25] suggested the role of TGF- $\beta_{1}$ as a fibrogenesis mediator. Nonetheless, the exact role that TGF- $\beta_{1}$ plays in bone marrow fibrosis remains elusive. Moreover, the results presented here agreed with previous reports [26] and further confirmed that high expression of TGF- $\beta_{1}$ is associated with bone marrow fibrosis. This is supported by the results obtained from the fibrogenic group and contrasted with those from the negative adenoviral vector (AdDL70), which neither increased TGF- $\beta_{1}$ concentration nor produced tissue fibrosis, endorsing a nonviral effect. The positive results from the profibrotic group were also contrasted with the results from the control animals. The latter did not stimulate tissue fibrosis, discouraging any suggestion that tissue fibrosis observed in the fibrogenic group could be a reaction to the injection. In addition, the rodent model of TGF- $\beta_{1}$ mediated bone marrow fibrosis reported here presented many of the features of myelofibrosis in other animal models reported in the literature [1].

In the present work, it was also shown that the surgical procedure carried out to deliver the adenoviral-mediated TGF- $\beta_{1}$ transfer was effective and did not cause major discomfort or pain in rats during or after surgery, and that the genes overexpressed. A surgical technique was previously reported to deliver an adenoviral-mediated gene transfer via the portal vein of rats to treat liver fibrosis [12]. However, until now no in vivo surgical method injecting AdTGF- $\beta_{1}$ directly into the bone marrow of rats to stimulate TGF- $\beta_{1}$ expression and induce 
tissue fibrosis has been reported in the literature [9-11]. The present work showed a suitable method to deliver an encoded adenovirus into the bone marrow of long bones of rats. The surgical technique was consistently reproduced in 42 animals and the fact that there were no complications during surgery and postsurgery periods confirmed that the technique could be reproduced and easily performed and caused no damage either to the animals or the target tissue. Furthermore, CT scan imaging revealed a clear entrance through the bone into the bone marrow area, and the histological results confirmed that the intrabone marrow injection effectively delivered the adenoviral vector to the target tissue. Therefore, it is proposed that this methodology is suitable to investigate the pathological pathway of bone marrow fibrosis in rats.

The methodology presented here succeeded in establishing a new technique to characterize TGF- $\beta_{1}$ and induce bone marrow fibrosis by delivering an adenoviral vector via intrabone marrow injection, which leads to a higher concentration of the cytokine active form. Moreover, the current technique is a reproducible and suitable surgical technique to deliver encoded adenoviruses into the bone marrow without disturbing the bone marrow area during surgery and with no postsurgery complications. In addition, the costs of the procedure were low compared to those of previous studies $[8,11]$, thus it allowed the reproduction of the same surgery using several animals.

In conclusion, the results obtainable produced insights into the association of TGF- $\beta_{1}$ with progressive bone marrow fibrosis. Therefore, the animal model presented here can also be used to study the role of TGF- $\beta_{1}$ and other cytokines in bone marrow fibrotic disorders. Therefore, it is suggested to use the methodology presented here for future animal studies aiming at further elucidating the physiopathology of bone marrow fibrosis, using rats as animal models.

\section{Acknowledgements}

We thank Duncan Chong and Xueya Feng for their technical support and Mary Jo Smith for her help with the processing of the histological samples. The authors would like to thank Dr. Shannon Martinson, Clinical Veterinary Pathologist from the Atlantic Veterinary College, for her technical assistance in the histological analysis. We also wish to express our gratitude to Chantal Saab for her help with the CT scanning procedure.

\section{References}

1 Tefferi A: Pathogenesis of myelofibrosis with myeloid metaplasia. J Clin Oncol 2005;23:8520-8530.

- 2 Reilly JT: Pathogenesis of idiopathic myelofibrosis: role of growth factors. J Clin Pathol 1992;45:461-464.

3 Mesa RA: The therapy of myelofibrosis: targeting pathogenesis. Int J Hematol 2002;76(suppl 2):296-304.

- 4 Dingli D, Mesa RA, Tefferi A: Myelofibrosis with myeloid metaplasia: new developments in pathogenesis and treatment. Inter Med 2004;7:540-547.

- 5 Hou Z, Nguyen Q, Frenkel B, Nilsson SK, Milne M, van Wijnen AJ, Stein JL, Quesenberry P, Lian JB, Stein GS: Osteoblast-specific gene expression after transplantation of marrow cells: implications for skeletal gene therapy. Proc Natl Acad Sci 1999:13:7294-7299.

6 Eto Y, Yoshioka Y, Mukai Y, Okada N, Nakagawa, S: Development of PEGylated adenovirus vector with targeting ligand. Int J Pharm 2008;354:3-8.

- 7 Kurata H, Liu CB, Valkova J, Koch AE, Yssel H, Hirabayashi Y, Inoue T, Yokota T, Arai K: Recombinant adenovirus vectors for cytokine gene therapy in mice. J Allergy Clin Immunol 1999;103:S471-S484.

8 Foley R, Ellis R, Walker I, Wan Y, Carter R, Boyle M, Braciak T, Addison C, Graham F, Gauldie J: Intramarrow cytokine gene transfer by adenoviral vectors in dogs. Hum Gene Ther 1997;8:545-553.

9 McCauslin CS, Wine J, Cheng L, Klarmann KD, Candotti F, Clausen PA, Spence SE, Keller JR: In vivo retroviral gene transfer by direct intrafemoral injection results in correction of the SCID phenotype in Ja3 knock-out animals. Blood 2003;102:843-848. 
$>10$ Li W, Xu T, Wang JF, Wu XF, Li M, Lu PY: Gene transfer using recombinant simian virus 40 viral vectors into mice bone marrow progenitor cells depressed the immunogenicity of keratinocyte stem cells. Transplant Proc 2008;40:3656-3659.

11 Liu B, Daviau J, Nichols CN, Strayer DS: In vivo gene transfer into rat bone marrow progenitor cells using rSV40 viral vectors. Blood 2005;106:2655-2662.

12 Lan L, Chen Y, Sun C, Sun Q, Hu J, Li D: Transplantation of bone marrow-derived hepatocyte stem cells transduced with adenovirus-mediated $I L-10$ gene reverses liver fibrosis in rats. Transpl Int 2008;21:581-592.

13 Bock O, Höftmann J, Theophile K, Hussein K, Wiese B, Schlué J, Kreipe H: Bone morphogenetic proteins are overexpressed in the bone marrow of primary myelofibrosis and are apparently induced by fibrogenic cytokines. Am J Pathol 2008;172:951-960.

14 Gastinne T, Vigant F, Lavenu-Bombled C, Wagner-Ballon O, Tulliez M, Chagraoui H, Velleval JL, Lacout C, Perricaudet M, Vainchenker W, Benihoud K, Giraudier S: Adenoviral-mediated TGF- $\beta_{1}$ inhibition in a mouse model of myelofibrosis inhibit bone marrow fibrosis development. Exp Hematol 2007;35:64-74.

15 Olfert ED, Cross BM, McWilliam: Guide to the care and use of experimental animals, 1993. Canadian Council on Animal Care. http://www.ccac.ca/en/CCAC_Programs/Guidelines_Policies/GUIDES/ENGLISH/toc_v1. htm (accessed December 2012).

-16 Sime PJ, Xing Z, Graham FL, Csaky KG, Gauldie J: Adenovector-mediated gene transfer of active transforming growth factor-beta1 induces prolonged severe fibrosis in rat lung. J Clin Invest 1997;100:768-776.

17 Bett AJ, Haddara W, Prevec L, Graham FL: An efficient and flexible system for construction of adenovirus vectors with insertions or deletions in early regions 1 and 3. Proc Natl Acad Sci USA 1994;91:8802-8806.

18 Xing Z, Ohkawara Y, Jordana M, Graham F, Gauldie J: Transfer of granulocyte-macrophage colony-stimulating factor gene to rat lung induces eosinophilia, monocytosis, and fibrotic reactions. J Clin Invest 1996;97:11021110 .

19 Koopmans SM, van Marion AMW, Schouten HC: Myeloproliferative neoplasia: a review of clinical criteria and treatment. J Med 2012;70:157-167.

20 Chagraoui H, Komura E, Tulliez M, Giraudier S, Vainchanker W, Wendling F: Prominent role of TGF- $\beta_{1}$ in thrombopoietin-induced myelofibrosis in mice. Blood 2002;100:3495-3503.

21 Bousse-Kerdiles MC, Martyre MC: Myelofibrosis: pathogenesis of myelofibrosis with myeloid metaplasia. French INSERM Research Network on Myelofibrosis with Myeloid Metaplasia. Springer Semin Immunopathol 1999;21:491-508.

22 Hasselbalch H, Junker P, Horslev-Petersen K, Lisse I, Bentsen KD: Procollagen type III aminoterminal peptide in serum in idiopathic myelofibrosis and allied conditions: relation to disease activity and effect of chemotherapy. Am J Hematol 1990;33:18-26.

23 Vener C, Fracchiolla NS, Gianelli U, Calori R, Radaelli F, Iurio A, Caberlon S, Gerli G, Boiocchi L, Delillers GL: Prognostic implications of the European consensus for grading bone marrow fibrosis in chronic idiopathic myelofibrosis. Blood 2008;4:1862-1865.

24 Kaviratne M, Hess M, Leusink M, Cheever AW, Davies SJ, McKerrow JH, Wakefield LM, Letterio JJ, Wynn T: IL-13 activates a mechanism of tissue fibrosis that is completely TGF- $\beta$ independent. J Immunol 2004;173:40204029.

25 Kreipe H, Büsche G, Bock O, Hussein K: Myelofibrosis: molecular and cell biological aspects. Fibrogenesis Tissue Repair 2012;5(suppl 1):S21.

26 Roberts AB, Sporn MB, Assoian RK, Smith JM, Roche NS, Wakefield LM, Heine UI, Liotta LA, Falanga V, Kehrl $\mathrm{JH}$, Fauci AS: Transforming growth factor type beta: rapid induction of fibrosis and angiogenesis in vivo and stimulation of collagen formation in vitro. Proc Natl Acad Sci USA. 1986;83:4167-4171. 